\title{
Modeling and Validation of 2-DOF Rail Vehicle Model Based on Electro-Mechanical Analogy Theory Using Theoretical and Experimental Methods
}

\author{
Fatih Pehlivan \\ Faculty of Engineering \\ Department of Mechanical Engineering \\ Karabuk University \\ Karabuk, Turkey \\ fatihpehlivan@karabuk.edu.tr
}

\author{
Cihan Mizrak \\ Faculty of Engineering \\ Department of Mechatronic Engineering \\ Karabuk University \\ Karabuk, Turkey \\ cihanmizrak@karabuk.edu.tr
}

\author{
Ismail Esen \\ Faculty of Engineering \\ Department of Mechanical Engineering \\ Karabuk University \\ Karabuk, Turkey \\ iesen@karabuk.edu.tr
}

\begin{abstract}
This paper presents theoretical and experimental results on modeling and simulation of two degrees of freedom rail vehicle by using electro-mechanical similarity theory. In this study, the equations of motion were derived using Newton's second law of motion and then mechanical and equivalent electrical circuits were obtained with the help of a free body diagram. A schema in Simulink allowing analyzing of the behavior of the primary and secondary suspension was created. In order to verify the electrical model, transfer function and schema were developed in Simulink. The simulation results were compared with the experimental data and the comparison showed that the results of the mechanical experiments were close to the simulation results, but the electrical results showed better periodic behavior.
\end{abstract}

Keywords-electro-mechanical analogy; equivalent electrical circuit; modeling; simulation; simulink; vehicle; suspension

\section{INTRODUCTION}

Urban and intercity transportation have been provided by highways in many countries and so issues regarding traffic congestion, traffic accidents and increasing transportation cost are emerging. In developed countries, railway transport systems are preferred for either urban or intercity transportation because of the fact that they are one of the safest and the most economical transport modes [1-3]. Recently the demand for railway transport systems has increased globally. The most crucial effect determining the driving safety and ride comfort is vehicle vibrations caused by dynamic forces occurring during movement. It was shown that during movement, vibrations occur due to dynamic forces usually caused by wheel-rail interaction [4-7]. This vertical oscillation of the rail vehicle can be minimized by optimizing spring stiffness and damping coefficient of the shock absorber as shown in [8, 9]. Models with various degrees of freedom (DOF) were examined to determine the dynamic behavior of the rail vehicles in [10]. Authors in [7] realized dynamic solutions of rail vehicles from single-DOF to multi-DOF and also worked on rail-wheel contact problems. Authors in [11] studied the dynamic behavior of two degrees of freedom (2-DOF) wagon models under random vibrations. Authors in [12] designed the vehicle suspension system of the quarter vehicle model in Matlab/Simulink and MSC-ADAMS and compared the results. The mathematical model of the system was created using the state space model and the vibration of the system was investigated by the unit step input function. Authors in [13] studied the mathematical modeling and simulation of a quartercar with two DOF. The state space mathematical model of the system was derived using Newton's second law of motion and free-body diagram. Afterwards, the performance of the system was examined with Matlab/Simulink. Passive, semi-active and active suspension systems have been tested with unit step input function. Authors in [14] studied the effect of spring and damping coefficients on acceleration and deflection using Matlab/Simulink. Authors in [15] aimed to improve driving comfort and road handling. Authors in [16] modeled a wagon moving on a bridge considered to be an elastic beam and done some calculations in terms of vibration and acoustics. They also calculated the response of the harmonic force that comes from the bridge and the rail. Authors in [17] studied the responses of the contact force and displacement caused by wheel-rail interaction. Analysis of the 5-DOF quarter-rail model supported by a 3-layer rail system was examined by using the equations of motion of vehicle and rail.

Most of the studies performed regarding rail vehicles have been related to keeping the vehicle vibrations at optimum level. In this paper, vehicle vibrations were studied, however, results were achieved by creating not only mechanical prototypes but also their equivalent electrical circuits. Experimental data obtained from the mechanical mechanism or the equivalent electrical circuit were compared with the simulation results.

\section{MODEL OF THE SYSTEM}

\section{A. Mathematical Model of the 2-DOF Rail Vehicle}

In order to constitute the mathematical model of the rail vehicle, it is beneficial to understand the quarter, half and full car models which are widely used in the literature due to their similarity with the models of rail vehicles. The modeled 2-DOF 
rail vehicle shown in Figure 1(a), consists of two masses: $m_{1}$ is the mass representing the rail vehicle body or wagon and $m_{2}$ is the mass representing the bogie system. $\mathrm{k}_{1}$ and $\mathrm{b}_{1}$ are the stiffness and damping coefficients of the secondary suspension respectively, $k_{2}$ and $b_{2}$ are the stiffness and damping coefficients of the primary suspension respectively, $\mathrm{x}_{1}$ and $\mathrm{x}_{2}$ are the vertical displacements of the rail vehicle body and the bogie system respectively and y is rail excitation as shown in [18-20]. D'Alembert's principle was used to draw the freebody diagram of this system shown in Figure 1(b).

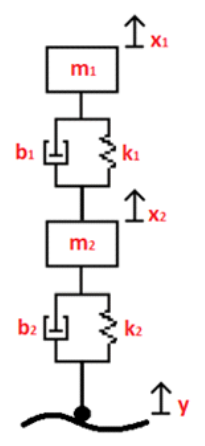

(a)

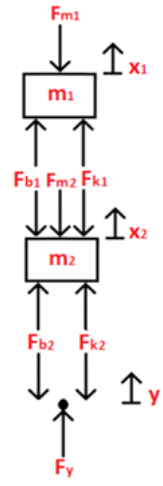

(b)
Fig. 1. (a) The 2-DOF rail vehicle model. (b) Vehicle free body diagram.

Accordingly, the equations for the vertical motion of the rail vehicle body and the bogie system are obtained by (1) and (2):

$$
\begin{aligned}
& k_{1}\left(x_{2}-x_{1}\right)+b_{1}\left(\dot{x}_{2}-\dot{x}_{1}\right)-m_{1} \ddot{x}_{1}=0 \\
& k_{2}\left(y-x_{2}\right)+b_{1}\left(\dot{y}-\dot{x}_{2}\right)-k_{1}\left(x_{2}-x_{1}\right) \\
& -b_{1}\left(\dot{x}_{2}-\dot{x}_{1}\right)-m_{2} \ddot{x}_{2}=0
\end{aligned}
$$

\section{B. Mechanical and Equivalent Electrical Circuit}

Substituting values in (3), (4) and (5), the force representation for the 2-DOF rail vehicle can be written as:

$$
\begin{aligned}
& F_{k_{1}}+F_{b_{1}}-F_{m_{1}}=0 \\
& F_{k_{2}}+F_{b_{2}}-F_{m_{2}}-F_{k_{1}}-F_{b_{1}}=0 \\
& F_{y}-F_{k_{2}}-F_{b_{2}}=0
\end{aligned}
$$

The mechanical circuit of the system is obtained using (3), (4) and (5) as shown in Figure 2.

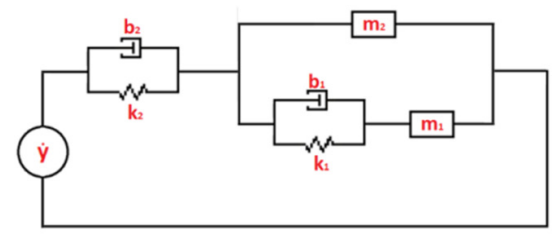

Fig. 2. The mechanical circuit of the modeled rail vehicle with 2 DOF.

Mechanical systems have one excitation source (force), while electrical systems have two excitation sources (voltage difference and current). In this sense, mechanical systems have two different electrical counterparts. The first similarity theory developed to find the first electrical charge is obtained by using the force-voltage difference similarity and the Kirchoff voltage law (KVL). To find the other electrical counterpart, the second theory of similarity is established, the force-flow similarity and the Kirchoff current law (KCL) are used [21]. The electrical responses of the mechanical elements in both theories are obtained by (6)-(8) which are generated using Kirchoff's laws and are shown in Table I:

$$
\begin{aligned}
& F(t)=m \dot{v}(t)+b v(t)+k \int v(t) d t \\
& V(t)=L \frac{d I(t)}{d t}+R I(t)+\frac{1}{C} \int I(t) d t \\
& I(t)=C \frac{d V(t)}{d t}+\frac{V(t)}{R}+\frac{1}{L} \int V(t) d t
\end{aligned}
$$

TABLE I. ANALOGOUS QUANTITIES

\begin{tabular}{|c|c|c|}
\hline Mechanical Quantity & $\begin{array}{c}\text { Electrical Quantity } \\
\text { (1st similarity theory) }\end{array}$ & $\begin{array}{c}\text { Electrical Quantity } \\
\text { (2nd similarity theory) }\end{array}$ \\
\hline Force (F) & Voltage (V) & Current (I) \\
\hline Velocity (v) & Current (I) & Voltage (V) \\
\hline Mass (m) & Inductance (L) & Capacitance (C) \\
\hline Friction (b) & Resistance (R) & Inverse Resistance (1/R) \\
\hline Spring constant (k) & $\begin{array}{c}\text { Inverse Capacitance } \\
(1 / \mathrm{C})\end{array}$ & Inverse Inductance (1/L) \\
\hline
\end{tabular}

Here, the second theory is selected to be applied to the modeled 2-DOF rail vehicle. According to the velocity-voltage similarity or the second similarity theory, the connections in parallel or serial of the mechanical circuit will be the same for the electrical system and so the electrical equivalent circuit of the rail vehicle is obtained by using the mechanical circuit of the system shown in Figure 2. The obtained circuit illustrated in Figure 3, and consists of two capacitances: $\mathrm{C}_{1}$ is mass representing rail vehicle body or wagon and $\mathrm{C}_{2}$ is mass representing the bogie system. $\mathrm{L}_{1}$ and $\mathrm{R}_{1}$ are the inductance and resistance stiffness and damping coefficients of secondary suspension respectively, $\mathrm{L}_{2}$ and $\mathrm{R}_{2}$ are the stiffness and damping coefficients of primary suspension respectively, and $\mathrm{V}$ is the excitation voltage.

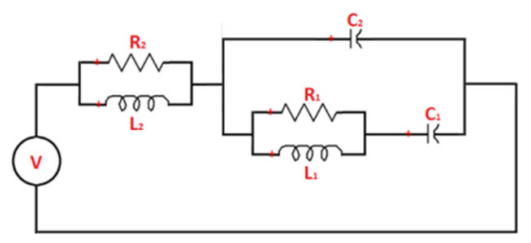

Fig. 3. The mechanical circuit of the modeled 2-DOF rail vehicle.

\section{Theoretical Methods}

In order to check the theoretical implementations of the system, a crank-connecting rod mechanism is considered for a harmonic rail excitation in the design of the mechanical system because it is simple and the most fundamental mechanism to transform the rotary motion to translational motion or vice versa [22]. The trigonometric method is used for the kinematic analysis and the velocity of the wheel is calculated for the rail excitation as shown in the following equations:

$$
x=R \cos \theta+\xi \cos \phi
$$




$$
\begin{aligned}
& \cos \phi=\sqrt{1-\sin ^{2} \phi} \\
& \frac{\sin \phi}{R}=\frac{\sin \theta}{l} \\
& \cos \phi=\sqrt{1-\left(\frac{R}{l}\right)^{2} \sin ^{2} \theta} \\
& x=R \cos \theta+\xi \sqrt{1-\left(\frac{R}{l}\right)^{2} \sin ^{2} \theta} \\
& x=R \cos \theta+\sqrt{\xi^{2}-\xi^{2}\left(\frac{R}{l}\right)^{2} \sin ^{2} \theta} \\
& \dot{x}=-R \dot{\theta} \sin \theta+\frac{d}{d t}\left(\sqrt{\left.\xi^{2}-\varepsilon^{2} R^{2} \sin ^{2} \theta\right)}\right. \\
& \dot{x}=-R \dot{\theta} \sin \theta+\frac{\left(-\dot{\theta} \varepsilon^{2} R^{2} \sin ^{2} \theta\right)}{2 \sqrt{\xi^{2}-\varepsilon^{2} R^{2} \sin ^{2} \theta}}
\end{aligned}
$$

The 2-DOF rail vehicle consists of three main parts representing rail actuator, rail vehicle body and bogie system. They are separately designed and assembled together with other parts such as suspension, step motor, linear bearing etc. Figure 4 shows the assembly view of the designed parts of the objective rail vehicle.

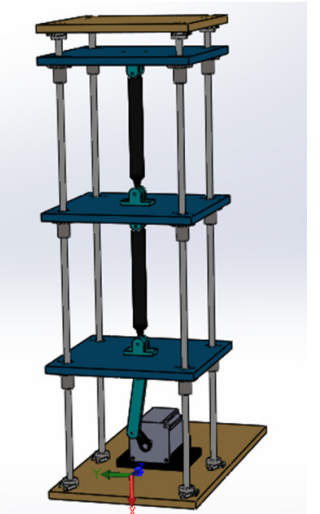

Fig. 4. The designed 2-DOF rail vehicle.

\section{Transfer Function of the Designed System}

Taking the Laplace transformation of (1) and (2), either the connection between the rail vehicle body and bogie system or the connection between the bogie system and the rail actuator are found as in the following equations. Equation (23) gives the transfer function of the 2-DOF rail vehicle:

$$
\begin{aligned}
& k_{1} X_{2}(s)-k_{1} X_{1}(s)+b_{1} s X_{2}(s)-b_{1} s X_{1}(s)=m_{1} s^{2} X_{1}(s) \\
& X_{2}(s)=\left[\frac{m_{1} s^{2}+b_{1} s+k_{1}}{b_{1} s+k_{1}}\right] X_{1}(s) \\
& k_{2}\left[Y(s)-X_{2}(s)\right]+b_{2} s\left[Y(s)-X_{2}(s)\right] k_{1}\left[X_{1}(s)-X_{2}(s)\right] \\
& \quad+b_{1} s\left[X_{1}(s)-X_{2}(s)\right]=m_{2} s^{2} X_{2}(s) \\
& \quad\left(b_{2} s+k_{2}\right) Y(s)+\left(b_{1} s+k_{1}\right) X_{1}(s)=\left[m_{2} s^{2}+\right. \\
& \left.\left(b_{1}+b_{2}\right) s+\left(k_{1}+k_{2}\right)\right] X_{2}(s) \\
& \quad\left(b_{2} s+k_{2}\right) Y(s)+\left(b_{1} s+k_{1}\right) X_{1}(s)=\left[m_{2} s^{2}+\right. \\
& \left.\left(b_{1}+b_{2}\right) s+\left(k_{1}+k_{2}\right)\right]\left[\frac{m_{1} s^{2}+b_{1} s+k_{1}}{b_{1} s+k_{1}}\right] X_{1}(s) \\
& \quad \frac{X_{1}(s)}{Y(s)}=\frac{b_{1} b_{2} s^{2}+\left(b_{2} k_{1}+b_{1} k_{2}\right) s+k_{1} k_{2}}{\left(m_{1} m_{2}\right) s^{4}+(A) s^{3}+(B) s^{2}+(C) s+k_{1} k_{2}} \\
& \text { where: } A=m_{2} b_{1}+m_{1} b_{1}+m_{1} b_{2}, B=m_{2} k_{1}+b_{1} b_{2}+m_{1} k_{1}+ \\
& m_{1} k_{2} \text {, and } C=b_{2} k_{1}+b_{1} k_{2} \\
& G(s)=\frac{X_{1}(s)}{Y(s)}=\frac{\dot{X}_{1}(s)}{\dot{Y}(s)} \quad \mathrm{S}
\end{aligned}
$$

\section{E. Mathematical Model of the System in MATLAB Simulink}

Simulink offers a graphical solution for modeling, simulating and analyzing dynamic systems over customizable blocks and tool library [23]. A Simulink model of the system is created using the mathematical model obtained through (1) and (2) as shown in Figure 6.

\section{F. Result of the Theoretical Methods in MATLAB Simulink}

In order to verify the electrical model, a transfer function and a model were developed in Simulink as shown in Figure 5. The results were obtained by using (16) for the rail excitation and the system parameters shown in Table II. Figure 7 shows the vertical displacement of the rail vehicle body with time and it is seen that the transfer function and the Simulink model of the mechanical system have one-to-one correspondence with the electrical model of the system.

\section{EXPERIMENTAL STUDY}

Experiments were conducted to validate both mechanical and electrical approaches. The 2-DOF rail vehicle model prototype was created. The theoretical study and the parameters shown in Table II were used in simulations to compare the experimental results with the theoretical ones.

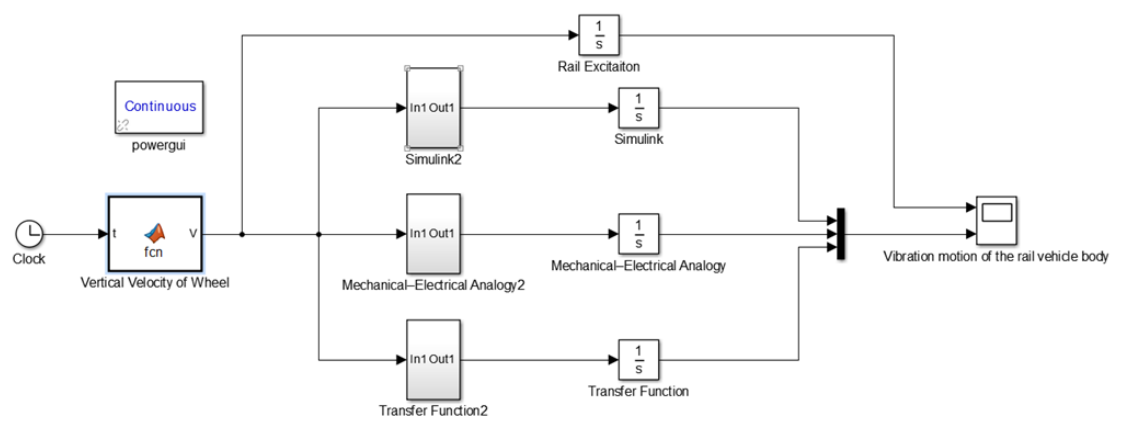

Fig. 5. Matlab representation of the electrical model, the transfer function and the Simulink model of the system 


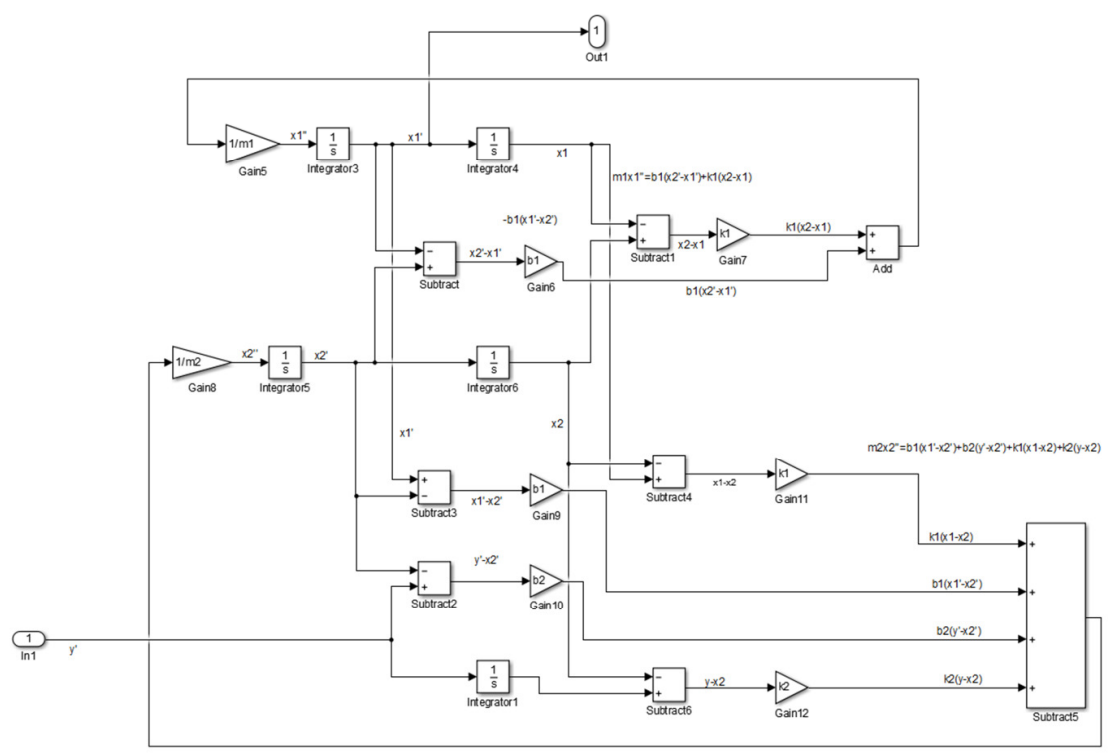

Fig. 6. Mathematical model of the system in Simulink.

TABLE II. PARAMETER VALUES USED IN THE 2-DOF RAIL VEHICLE

\begin{tabular}{|c|c|}
\hline Parameters & Values \\
\hline Mass of the rail vehicle body or wagon, $\mathrm{m}_{1}$ & $0,794 \mathrm{~kg}$ \\
\hline Damping coefficients of secondary suspension, $\mathrm{b}_{1}$ & $57,53 \mathrm{~N} . \mathrm{s} / \mathrm{m}$ \\
\hline Stiffness of secondary suspension, $\mathrm{k}_{1}$ & $400 \mathrm{~N} / \mathrm{m}$ \\
\hline Mass of the bogie system, $\mathrm{m}_{2}$ & $0,748 \mathrm{~kg}$ \\
\hline Damping coefficients of primary suspension, $\mathrm{b}_{2}$ & $57,53 \mathrm{~N} . \mathrm{s} / \mathrm{m}$ \\
\hline Stiffness of primary suspension, $\mathrm{k}_{2}$ & $400 \mathrm{~N} / \mathrm{m}$ \\
\hline Crank length, $\mathrm{R}$ & $0,025 \mathrm{~m}$ \\
\hline Connecting rod length, 1 & $0,084 \mathrm{~m}$ \\
\hline Engine speed, $\dot{\theta}$ & $74 \mathrm{rpm}$ \\
\hline
\end{tabular}

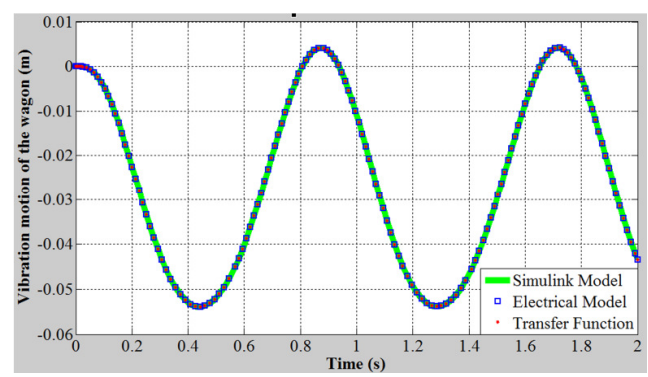

Fig. 7. Verification of the electrical model of the system by using the transfer function and the Simulink model.

\section{A. Mechanical Test Rig}

The design of the experimental prototype, which comprises the primary and secondary suspension mechanisms and the excitation mechanism, is shown in Figure 8. Aluminum shock absorbers, stepper motor and its drive module, control card, chromium rods, linear bearings, rod holders, power supply and vibration datalogger were used in the design. The parts representing the rail excitation, the bogie and the wagon were made up of particle board. It was preferred because it is lighter than all other metals, including aluminum and is more rigid than composite or plastic. Mechanical vibration experiments were performed on the prototype rail vehicle test rig shown in Figure 9. In the mechanical test rig, a stepper motor controls the rail excitation by using a crank-connecting rod mechanism and the bottom particle board which is below the primary suspension and provides the excitation as velocity to the system. In this way, both primary and secondary suspensions start to move and acceleration of the wagon which is the top particle board is taken with vibration datalogger mounted to the wagon.

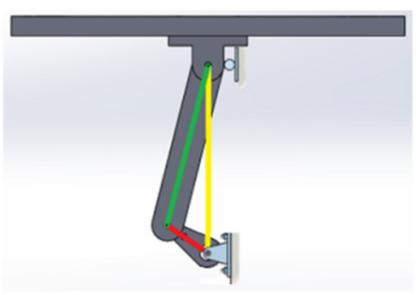

(a)

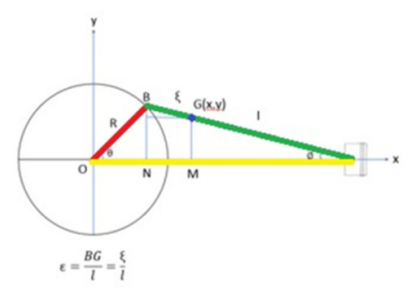

(b)
Fig. 8. (a) Crank-connecting rod mechanism, (b) kinematic analysis.

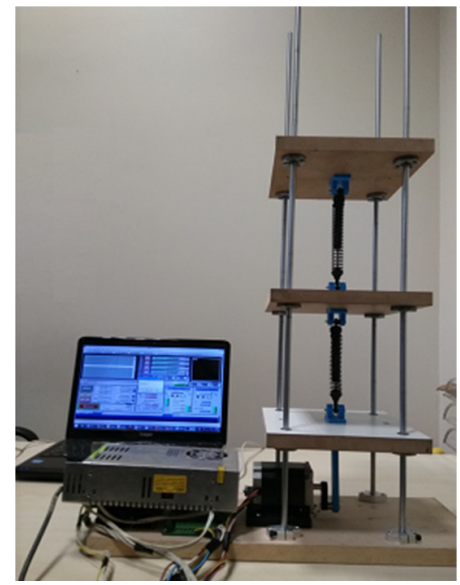

Fig. 9. Mechanical test rig 


\section{B. Electrical Test Rig}

To verify the theoretical study and the designed and manufactured prototype of the 2-DOF mechanical rail vehicle model, it is necessary to establish the equivalent electrical test rig of the system. For this purpose, the first step is to create voltage representing the rail excitation. An arbitrary voltage generator can supply the existing excitation because of the fact that it can produce periodic signals as the rail excitation in the mechanical test rig. An AA Tech AWG-1020 function generator was used in the experiments. The current excitation signal was generated as shown in Figure 10 via Easywave software and was sent to the voltage generator.

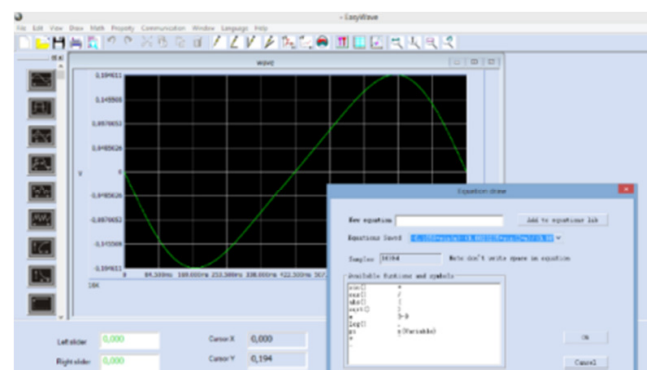

Fig. 10. The electrical excitation signal

For convenience, the electrical parameters were selected such that the ratio of electrical parameters and their representing mechanical parameters be 1:100, which means $1 \mathrm{~kg}$ corresponds to $0.01 \mathrm{~F}$ etc. The parameter values are shown in Table III. Except for the inductance element, all values shown in Table III were obtained with elements available in the market. In this study, two inductance elements having values of $250 \mathrm{mH}$ were needed. An inductor of this value is difficult to find on the market and it is obtained by wrapping copper wire on ferrite [24]. The number of turns is calculated by using (24):

$$
N=\sqrt{\frac{L}{A_{L}}}
$$

where $L$ is the desired inductance value and $A_{L}$ is the magnetic conductivity. The magnetic conductivity of the ferrite used to wrap the copper wire is $24700 \times 10^{-9} \mathrm{H}$. The electrical experiments were performed on the created electrical circuit shown in Figure 11. Using the GW INSTEK GDS-1102-U digital oscilloscope, the voltage values on the capacitor $\left(\mathrm{C}_{1}\right)$, which is the electrical equivalent of the wagon, were measured and transferred to the Freewave software and experimental data were obtained.

TABLE III. PARAMETER VALUES USED IN THE 2-DOF RAIL VEHICLE

\begin{tabular}{|c|c|c|}
\hline Equivalent & Parameter & Used Values \\
\hline Wagon mass, $\mathrm{C}_{1}$ & Capacitor & $0,008 \mathrm{~F}$ \\
\hline $\begin{array}{c}\text { Damping coefficients of secondary } \\
\text { suspension, } \mathrm{R}_{1}\end{array}$ & Resistor & $1,7424 \Omega$ \\
\hline Stiffness of secondary suspension, $\mathrm{L}_{1}$ & Inductor & $0,25 \mathrm{H}$ \\
\hline Mass of the bogie system, $\mathrm{C}_{2}$ & Capacitor & $0,0075 \mathrm{~F}$ \\
\hline $\begin{array}{c}\text { Damping coefficients of primary } \\
\text { suspension, } \mathrm{R}_{2}\end{array}$ & Resistor & $1,7424 \Omega$ \\
\hline Stiffness of primary suspension, $\mathrm{L}_{2}$ & Inductor & $0,25 \mathrm{H}$ \\
\hline
\end{tabular}

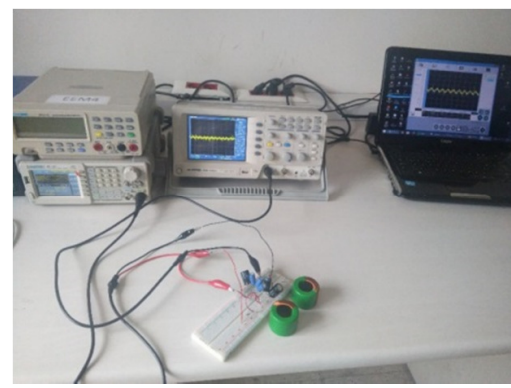

Fig. 11. Electrical equivalent circuit set up

\section{RESUlTS}

To compare the experimental results with the theoretical mechanical and electrical approach, a series of simulations were conducted in Matlab. The vertical vibrations obtained from the mechanical experiment (Figure 12) and the vertical vibrations obtained from the electrical experiment (Figure 13) were compared with the simulation results.

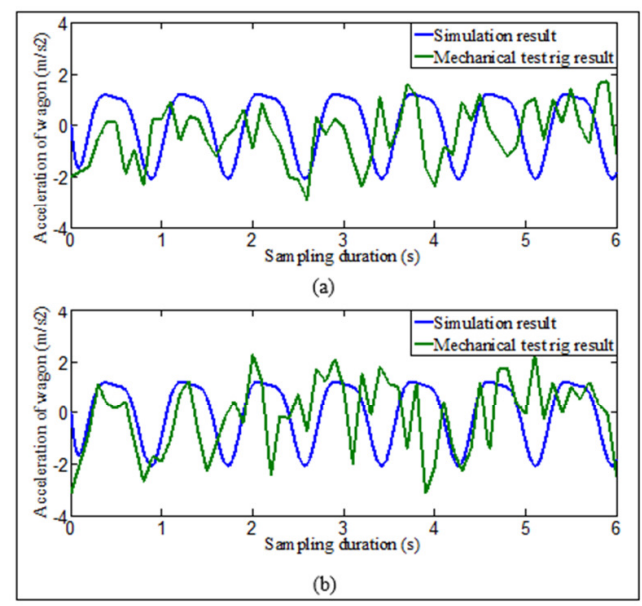

Fig. 12. Mechanical experiment and theoretical results comparison of vibration values of the rail vehicle model (a) first and (b) second experiment.

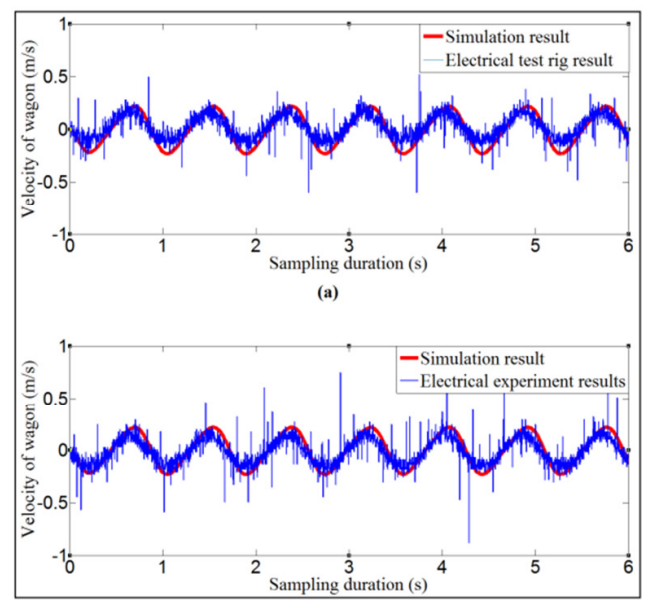

Fig. 13. Electrical experiment and theoretical results comparison of vibration values of the rail vehicle model (a) first and (b) second experiment. 
Both experimental methods were applied two times and the sampling duration was $6 \mathrm{~s}$ in each experiment. When the rootmean-square (RMS) values of the vertical vibrations obtained from the mechanical test rig, the equivalent electrical test rig and the theoretical model were compared to each other, it was seen that the mechanical test rig and the theoretical methods had the same results by a maximum error of $9.23 \%$ as shown in Table IV. On the other hand, the maximum error was $25.71 \%$ when the equivalent electrical test rig was compared with the theoretical methods as shown in Table V.

TABLE IV. RMS-THEORITICALVALUE RESULT COMPARISON MECHANICAL TEST RIG

\begin{tabular}{|c|c|c|}
\hline & RMS Values & Error \\
\hline Mechanical test rig (1st experiment) & 1,084 & $6,47 \%$ \\
\hline Mechanical test rig (2nd experiment) & 1,266 & $9,23 \%$ \\
\hline Theoretical method & 1,159 & \\
\hline
\end{tabular}

TABLE V. RMS-THEORITICAL VALUE COMPARISON-EQUIVALENT ELECTRICAL TEST RIG

\begin{tabular}{|c|c|c|}
\hline & RMS Values & Error \\
\hline Equivalent electrical test rig (1st experiment) & 0,11717 & $25,71 \%$ \\
\hline Equivalent electrical test rig (2nd experiment) & 0,12749 & $19,17 \%$ \\
\hline Theoretical method & 0,15773 & \\
\hline
\end{tabular}

\section{CONCLUSION}

Two-DOF rail vehicle has been studied and modeled by mechanical test rig, its equivalent electrical circuit and theoretical methods. Both the mechanical test rig and its equivalent electrical circuit were validated by simulations and both methods were found to be capable of determining the vertical vibrations of both bogie and wagon. The mechanical test rig RMS results are closer to the simulation results in comparison with the electrical circuit, but the electrical results show better periodic behavior.

\section{REFERENCES}

[1] S. Bhattacharjee, A. R. Goetz, "Impact of light rail on traffic congestion in Denver", Journal Of Transport Geography, Vol. 22, pp. 262-270, 2012

[2] R. Lalive, S. Luechinger, A. Schmutzler, Does Supporting Passenger Railways Reduce Road Traffic Externalities?, University of Zurich, Working Paper Series, No. 110, University of Zurich, 2013

[3] M. Metin, Rayli Sistem Araclarının Modellenmesi ve Titresimlerinin Kontrolu, Yildiz Technical University, 2007 (in Turkish)

[4] A. Wijeweera, H. To, M. B. Charles, K. Sloan, "A time series analysis of passenger rail demand in major Australian cities", Economic Analysis And Policy, Vol. 44, No. 3, pp. 301-309, 2014

[5] E. Matsika, S. Ricci, P. Mortimer, N. Georgiev, C. O’Neill, "Rail vehicles, environment, safety and security", Research In Transportation Economics, Vol. 41, No. 1, pp. 43-58, 2013

[6] M. Graa, M. Nejlaoui, A. Houidi, Z. Affi, L. Romdhane, "Modeling and Simulation for Vertical Rail Vehicle Dynamic Vibration with Comfort Evaluation", in: Multiphysics Modelling and Simulation for Systems Design and Monitoring, Springer, 2015

[7] R. V. Dukkipati, V. K. Garg, Dynamics of Railway Vehicle Systems, Academic Press, 1984

[8] A. Orvnas, "Methods for Reducing Vertical Carbody Vibrations of a Rail Vehicle - A Literature Survey", in: Report in Railway Technology, KTH Engineering Sciences, 2010

[9] V. Barethiye, G. Pohit, A. Mitra, "A combined nonlinear and hysteresis model of shock absorber for quarter car simulation on the basis of experimental data", Engineering Science And Technology, An International Journal, Vol. 20, No. 6, pp. 1610-1622, 2017

[10] C. Mizrak, Orta Hizli Calışan Rayli Sistem Bojilerinin Titresimlerinin Modellenmesi ve Optimizasyonu, Karabuk University, 2015 (in Turkish)

[11] G. R. M. Mastinu, M. Gobbi, G. D. Pace, "Analytical formulae for the design of a railway vehicle suspension system", Journal Of Mechanical Engineering Science, Vol. 215, No. 6, pp. 683-698, 2001

[12] S. J. Chikhale, D. S. P. Deshmukh, "Comparative Analysis Of Vehicle Suspension System in Matlab-Simulink and MSc- Adams with the help of Quarter Car Model", International Journal Of Innovative Research In Science, Engineering And Technology, Vol. 2, No. 8, pp. 4074-4081, 2013

[13] P. Sathishkumar, J. Jancirani, D. John, S. Manikandan, "Mathematical modelling and simulation quarter car vehicle suspension", International Journal of Innovative Research in Science, Engineering and Technology, Vol. 3, No. 1, pp. 1280-1283, 2014

[14] K. K. Jagtap, D. R. Dolas, "Simulation of Quarter Car Model", International Journal Of Engineering Research And General Science, Vol. 3, No. 6, pp. 242-249, 2015

[15] A. Florin, M. R. Ioan-Cozmin, P. Liliana, "Pasive Suspension Modeling Using MATLAB, Quarter Car Model, Imput Signal Step Type”, New Technologies And Products In Machine Manufacturing Technologies, Romania, 2013

[16] N. Ouelaa, A. Rezaiguia, B. Laulagnet, "Vibro-acoustic modelling of a railway bridge crossed by a train", Applied Acoustics, Vol. 67, No. 5, pp. $461-475,2006$

[17] R. U. A. Uzzal, W. Ahmed, S. Rakheja, "Dynamic Analysis of Railway Vehicle-Track Interactions due to Wheel Flat with a Pitch-Plane Vehicle Model", Journal of Mechanical Engineering, Vol. 39, No. 2, pp. 86-94, 2008

[18] M. Metin, R. Guclu, "Vibrations control of light rail transportation vehicle via PID type fuzzy controller using parameters adaptive method", Turkish Journal of Electrical Engineering and Computer Sciences, Vol. 19, No. 5, pp. 807-816, 2011

[19] E. J. O'Brien, C. Bowe, P. Quirke, D. Cantero, "Determination of longitudinal profile of railway track using vehicle-based inertial readings", Journal of Rail and Rapid Transit, Vol. 231, No. 5, pp. 518534,2016

[20] C. Mizrak, I. Esen, "Determining Effects of Wagon Mass and Vehicle Velocity on Vertical Vibrations of a Rail Vehicle Moving with a Constant Acceleration on a Bridge Using Experimental and Numerical Methods", Shock And Vibration, Vol. 2015, Article ID183450, 2015

[21] X. Xu, H. Jiang, M. Gao, "Modeling and Validation of Air Suspension with Auxiliary Chamber Based on Electromechanical Analogy Theory", Applied Mechanics And Materials, Vol. 437, No. 1, pp. 190-193, 2013

[22] D. Hroncova, M. Binda, P. Sarga, F. Kicak, "Kinematical analysis of crank slider mechanism using MSC Adams/View", Procedia Engineering, Vol. 48, pp. 213-222, 2012

[23] A. Tandel, A. R. Deshpande, S. P. Deshmukh, K. R. Jagtap, "Modeling, Analysis and PID Controller Implementation on Double Wishbone Suspension Using SimMechanics and Simulink", Procedia Engineering, Vol. 97, pp. 1274-1281, 2014

[24] A. Goldman, Magnetic Components for Power Electronics, Springer, 2002 